\title{
DINÂMICA NA ÁREA CENTRAL DE FLORIANÓPÓLIS: REFLEXÃO SOBRE SEU PAPEL E SUA INSERÇÃO COMO LOCAL TURÍSTICO
}

\author{
Luana Emmendoerfer* \\ Vera Lúcia Nehls Dias**
}

Resumo: O objeto de estudo se concentra na área central e insular de Florianópolis, delimitada pelo prolongamento da Avenida Mauro Ramos até as Baías Norte e Sul, engloba o que se convencionou chamar de entorno próximo do núcleo histórico e a partir do qual ocorreu o crescimento da cidade. A escolha pelo estudo dessa área foi em parte, devido à principal atividade turística de Florianópolis estar relacionada às suas peculiaridades físiconaturais, muitas delas, inclusive, localizadas em balneários distantes. Tal maneira de aproveitamento e exploração do espaço geográfico acabou por relegar a área central da cidade a um segundo plano no contexto do processo de aproveitamento do lugar pelo setor turístico.

Palavra-chaves: Turismo; Área Central; Refuncionalização; Dinâmica Urbana.

\begin{abstract}
The focus of this article is the central area of Florianopolis, bounded by the extension of Mauro Ramos avenue up until Norte and Sul Bays, which encompasses what is conventionally called and known as the historical center's immediate borders, around which the city grew and developed. The choice of this particular area as the object of my studies was due to the fact that the city's main touristic activity is linked to its physical and natural peculiarities, many of which are located in distant bathhouses. This particular way of using and exploring the geographical space eventually contributed to the city's center abandonment in the context of its use as a tourist destination.
\end{abstract}

Keywords: Tourism, Central Area; Refunctioning; Urban Dynamics.

\begin{abstract}
A paisagem urbana, como a rural, não existe por si mesma. Ela é produto de uma determinada forma de ver a cidade, construída socialmente. Por isso mesmo, é importante recuperarmos, do passado, as vertentes ou origens da construção da paisagem na cidade contemporânea.
\end{abstract}

Nestor Goulart Reis Filho. Espaço e Memória (1994:167)

* Técnica Plena da atividade de Turismo Social do SESC/SC.

INTRATEXTOS, Rio de Janeiro. vol.2, nº 1, PP. 97 - 109, 2010. 


\section{Introdução}

O objeto de estudo se concentra na área central e insular de Florianópolis, delimitada pelo prolongamento da Avenida Mauro Ramos até as Baías Norte e Sul, engloba o que se convencionou chamar de entorno próximo do núcleo histórico e a partir do qual ocorreu o crescimento da cidade. A escolha pelo estudo dessa área foi em parte, devido à principal atividade turística de Florianópolis estar relacionada às suas peculiaridades físico-naturais, muitas delas, inclusive, localizadas em balneários distantes. Tal maneira de aproveitamento e exploração do espaço geográfico acabou por relegar a área central da cidade a um segundo plano no contexto do processo de aproveitamento do lugar pelo setor turístico.

É notório verificar que a área central de Florianópolis, objeto de estudo em questão, a partir dos anos 70 vem tomando dimensões surpreendentes, transformando-se em um espaço diferente de sua concepção original. Essas mudanças as quais podemos chamar de processos de urbanização são advindas da busca do progresso para a cidade tentando torná-la moderna e dinâmica para a população, adequando-a a um determinado projeto de revitalização.

Muitos autores observam que é na área central onde se pode perceber o reflexo e traços da gênese da cidade. Diante de todo seu processo histórico, formação e funcionalidade que este espaço apresenta é importante demonstrar o significado impresso nas suas transformações, pois como acrescenta Lacaze (1995) é na área central que se tem a identidade da cidade. Assim, da mesma forma que se apresenta enquanto referência para os cidadãos pode ser para o visitante uma "imagem resumida da cidade".

Em outras palavras é o que Vance, (1971) chama de "coração histórico da cidade". Nele se encontra o conjunto mais importante da área urbana no período que antecede a modernização. Segundo este autor, é o caráter paroquial da sociedade que antecede a modernização e transparece em sua organização espacial que acaba sendo substituído por um novo modo de vida, atribuindo à cidade uma função mais dinâmica.

Quando se trata de grandes cidades, capitais ou metrópoles pode-se pensar no centro como um aglomerado que inclui o centro histórico e os arrabaldes antigos, segundo Parenai (2006:76) são “Os bairros elegantes do século XIX, as expansões ordenadas da primeira metade do século XX, alguns setores que foram objeto de ações de renovação, uma parte dos bairros novos que substituíram antigas zonas industriais ou portuárias”.

** Professora titular na Universidade do Estado de Santa Catarina - UESC. 
De modo geral as áreas centrais das cidades possuem uma forte concentração de equipamentos públicos e de instituições públicas; a marcante presença de atividades comerciais; uma alta densidade de edificações onde coexistem edifícios antigos com outros novos e uma grande variedade e diversidade de usos.

Em face às perspectivas valorizadas do modernismo e do progresso, o "tecido antigo" é hoje visto como a "alma da cidade", existindo assim um consenso relativo à necessidade de assegurar a sua proteção e conservação, visto que o centro histórico, elemento integrante da área central, tornou-se apenas uma pequena parte da cidade e corre sérios riscos de se tornar mais visitado do que vivido, mais imagem que conteúdo (FERNANDES, 2000).

Assim Silva (1997) constata que o espaço da cidade fragmenta-se, e ao longo do tempo as paisagens que contêm os signos do cotidiano urbano impõe novos enfoques metodológicos e uma postura científica, na medida em que emergem novos campos de investigação e novas bases conceituais.

\section{1. Área central e dinâmica urbana}

O conhecimento da área central de Florianópolis envolve a dinâmica urbana dotada de novas transformações, bem como, merecem destaque a agregação de novas funcionalidades frente às atividades turísticas.

Para um melhor entendimento do processo de dinamização da área estudada torna-se importante destacar além do conceito de paisagem, os de espaço e lugar. Conceitos estes intrínsecos no estudo de caso analisado.

De acordo com Santos (1985) ao estudar o espaço é preciso considerá-lo em sua totalidade e fragmentá-los em partes para ser ter uma análise mais particular e assim depois de reconstituí-lo pelo processo de pensamento, formar o todo novamente.

Sabe-se que para Beltrão (1989) esta fragmentação não é aleatória, os elementos são representados e só podem ser entendidos através do passado e do presente, pois no movimento histórico dinâmico cada elemento muda seu papel e sua posição no sistema temporal e no sistema espacial e, a cada momento, o valor de cada qual deve ser tomado da sua relação com os demais elementos e com o todo.

Segundo Santos (1988), pode-se acrescentar que o espaço é entendido como um conjunto de formas contendo cada qual a fração da sociedade em movimento. É indispensável na sua formação a configuração territorial, isto é, o conjunto de dados naturais, mais ou 
menos modificados pelo homem e a dinâmica social ou conjunto de relações que definem uma sociedade em um dado momento.

Para isso, o espaço urbano neste estudo é entendido como sendo fragmentado diante das diversas temporalidades que compõem a configuração territorial da área central de Florianópolis. De maneira que, a convivência dos sedimentos remanescentes do passado da cidade com tempos mais recentes é capaz de revelar significados impressos na dinâmica própria das práticas sociais. Isso faz com que o espaço seja produzido como uma "realidade objetiva" (SOUZA, 1988) e que tenha uma "autonomia de existência" (SANTOS, 1978), ou seja, sua evolução particular e original se faz através da relação com outros dados da vida social, com base em fatos históricos próprios.

Considerando ainda o pensamento de Santos (1978), a paisagem representa diferentes momentos do desenvolvimento de uma sociedade. A paisagem seria então o resultado da acumulação dos tempos, sendo sua forma alterada, renovada, suprimida ou mantida em permanente modificação, para acompanhar as transformações da sociedade. Para cada lugar, cada porção do espaço, esta acumulação é diferente: os objetos não mudam no mesmo lapso de tempo, na mesma velocidade ou na mesma direção.

O mesmo autor (1994, p. 66) considera que "uma paisagem é uma escrita sobre a outra, é um conjunto de objetos que têm idades diferentes, é uma herança de muitos diferentes momentos", acrescentando que "Ela não é dada para todo o sempre, é objeto de mudança graças ao seu movimento funcional" (ibid, p. 68).

Dessa forma, pelo entendimento enunciado por Milton Santos, a paisagem da área central de Florianópolis é a que apresenta maior acumulação de tempos. É um lugar que vem sofrendo modificações e alterações por diversas ações do homem, buscando expressar em seu ambiente construído marcas da modernidade.

Desta maneira, a paisagem é abordada como uma síntese de uma história, um momento registrado compreendido como porções do espaço. Considera-se a dimensão real do concreto, aquilo que se vê como se fosse tirar uma fotografia. Assim na área central de Florianópolis temos várias paisagens que formam o espaço, muitas delas são "matéria-prima para o turismo em determinado lugar" (XAVIER, 2007). Na paisagem, os participantes do turismo se deslocam, valorizam seus produtos, modificam seus componentes lhes atribuindo valores econômicos, sociais, afetivos ou simbólicos. 
Já o conceito de lugar é outro aspecto importante a ser destacado nesta reflexão. O lugar pode ter várias dimensões de escala, sendo uma porção do espaço apropriada em seu sentido palpável, uma vez que ele é a base da reprodução da vida e seu sentido de concretude se dá pela relação que mantêm entre si. Para Santos (1978) o mundo se faz no lugar e o mundo funciona através das relações que nele se estabelecem.

Ainda pode-se ter a idéia do lugar como um local vivido. Carlos (1996, p. 21) confirma que: "São os lugares que o homem habita dentro da cidade que dizem respeito ao seu cotidiano e ao seu modo de vida onde se locomove, trabalha, passeia, flana, isto é, pelas formas através das quais o homem se apropria e que vão ganhando o significado dado pelo uso".

Por outro lado, Cruz (2007, p. 25) ao estudar a relação do lugar com o turismo propõe o termo "pseudo-lugares" " no sentido em que "são lugares cuja história e identidade são prostituídas em nome de um uso especializado de relações alienadas e alienígenas produzidas pelo e para o turismo". O que nos leva a pensar na apropriação do lugar e na produção dos mesmos exclusivos para uso turístico, como é o caso de empreendimentos hoteleiros.

Santos, em outra obra, acrescenta que "o lugar é um conjunto de objetos que têm autonomia de existência pelas coisas que o formam (...), todos os dias novas funções substituem as antigas, novas funções se impõem e se exercem” (1994, p. 52). E complementa ainda que “[...] cada lugar é singular (...), cada lugar combina de maneira particular variáveis que podem, muitas vezes, ser comuns a vários lugares" (ibid, p. 58).

Entende-se então que o lugar não é único, mas tem uma característica singular, nele está à ação combinada de processos universais, particulares e singulares. Desta maneira a área central também compreende um lugar, comum a outras cidades, porém torna-se singular por ter nele particulares que só são encontradas neste espaço (em Florianópolis) e principalmente pelas relações sociais que nele se desenvolvem, refletindo nas transformações do seu espaço, ainda mais com apelo turístico.

No centro florianopolitano estamos assistindo uma dinamização do lugar. O centro está sendo redescoberto, há uma revalorização de Florianópolis. Essa revitalização se dá por conta de algumas políticas setoriais, e muitas vezes estas ações acontecem por conta de

\footnotetext{
${ }^{1} \mathrm{O}$ termo utilizado pela autora rebate o conceito de "não-lugar"de Marc Augé, o qual sugere uma definição de lugar antropológico de forma generalizável. Portanto, optou-se pela expressão "pseudo-lugar" como um conceito mais apropriado para este estudo relacionado com o turismo.
} 
organizações não governamentais que as implementam. Algumas melhorias são feitas para a cidade não visando diretamente o turismo, no entanto, quase de maneira inevitável as transformações realizadas acabam por apresentar uma nova configuração com interesse turístico, onde a construção do espaço, com freqüência, é percebida pelos impactos que a atividade pode produzir nas pessoas e nos lugares.

Diante de uma conseqüência de aceleração do crescimento urbano ao longo do século XX, na medida em que neste atual momento a maior parte da população se encontra em área urbana e não mais em área rural, observa-se, paradoxalmente, que somente uma pequena parcela da população urbanizada se encontra na área central.

Percebe-se que a maior parte da população está fora do centro antigo, do local onde foi a gênese da cidade. As transformações do modo de vida e a constante introdução de novas modalidades de consumo vêm provocando uma grande expansão da superfície urbanizada. Ao mesmo tempo em que o centro perde seus habitantes ganha novas funções como, por exemplo, a revalorização dos antigos centros urbanos com vistas ao turismo e a recuperação da memória cultural da sociedade local.

Podemos destacar ainda que a inversão da relação centro x periferia revela fenômenos contraditórios. Por um lado temos a expansão do centro, por outro sua proporção na área urbanizada diminui. A área central continua a desempenhar um importante papel no plano social e em muitos casos está se revalorizando, mesmo quando sofre a concorrência de outras áreas da cidade.

Segundo Parenai (2006) a modificação da noção de centro pode ser interpretada como um ajuste histórico: o que ontem era novo tornou-se antigo. Porém, a dupla explosão - do conjunto arquitetônico e do tecido urbano - no processo de urbanização dos últimos trinta anos acrescenta uma ruptura morfológica quase irredutível, preservando em alguns lugares o traçado apenas das ruas e praças, ou seja, das áreas de espaço público e uso coletivo.

Dessa forma, percebe-se que o processo de ordenamento do território materializa-se no espaço e no tempo através da evolução da paisagem, refletindo as incidências, no campo estético e cultural, dos modelos subjacentes à organização deste território, sendo, simultaneamente, o resultado e o somatório das intervenções, individuais e coletivas, planejadas ou espontâneas.

Já com relação aos centros urbanos para Loureiro (2003, p. 26) estes desempenham um papel tanto integrador como simbólico: "Integrador na medida em que concentram muitas 
atividades urbanas, como comércio e serviço. Simbólico, porque as cidades latino-americanas concentram nessas áreas importantes edificações de inestimável valor histórico e cultural, representando a memória coletiva de seus habitantes".

Estas características de áreas centrais fazem pensar que uma das representações das cidades de colonização portuguesa, é a centralidade. No Brasil percebe-se que não ocorre diferente. $\mathrm{O}$ conjunto de sua paisagem urbana tem sua gênese numa praça central com uma igreja ao seu redor terminando com uma rua defronte ao mar. Os núcleos urbanos se formaram ao redor de uma praça central, de onde partiam as ruas e se estruturavam as quadras e os lotes (GUTIERREZ, 1989, p. 135).

Já os centros históricos normalmente inseridos nos centros urbanos, possuem importantes edificações histórico-culturais ao redor da praça matriz, no qual abrangem uma totalidade ou parte do centro social mais importante da cidade. Com relação às características do centro histórico é acrescentado:

\footnotetext{
É aquele que confere identidade a toda uma cidade, diferente de outras áreas históricas, pois estas dão identidade somente a seus próprios habitantes e de bairros próximos. Ele é diferenciado ainda por ser um assentamento humano cujas estruturas, ainda que se tenham transformado ao longo do tempo, constituem um valor especial como testemunho histórico ou por apresentarem características urbanísticas ou arquitetônicas particulares (LOUREIRO, 2003, p. 26).
}

Nota-se então que este espaço possui características que permitem verificar uma articulação das atividades urbanas, além de possuir uma identificação simbólica as quais proporcionam uma comunicação entre os atores que usam esta área. É onde ocorrem práticas sociais das mais diversas possíveis, marcando assim fatos e acontecimentos históricos que trazem testemunhos de uma formação cultural, artístico e até estéticos favorecendo assim qualidade de vida aos seus usuários que dão usos específicos a esta área.

\section{2. Área central e sua inserção como local turístico}

Segundo Cruz (2001), o turismo é em essência uma prática social, agregada ao mercado que tem no espaço seu principal objeto de consumo. E, em decorrência dessa característica intrínseca, requer a adaptação dos territórios e de suas demandas materiais e imateriais. 
As estratégias de intervenção e produção do espaço urbano têm uma das expressões deste processo na refuncionalização, sobretudo de patrimônios edificados dos centros históricos das cidades:

\footnotetext{
As políticas de redesenvolvimento das áreas centrais, antes abandonadas à deterioração, hoje são disputadas pelas atividades ditas nobres da "indústria cultural". A revalorização das paisagens constituídas por elementos históricos, como o patrimônio arquitetônico, tem atribuído às localidades urbanas contemporâneas novos sentidos no campo de aproveitamento do espaço para inserção de novas atividades (LUCHIARI, 2003, p. 243).
}

O patrimônio histórico arquitetônico segundo Cruz (2001) interessa ao turismo urbano, pois pode representar uma oportunidade de diversificação da oferta turística do lugar. Não por acaso, as estratégias voltadas à dinamização do turismo, apropriam-se desse patrimônio promovendo sua conservação/preservação e inserindo-o como possibilidade de produto oferecido ao turista e, muitas vezes, até mudando seu significado original.

É o que Milton Santos (1999) denominou de rugosidade ao se referir nas formas passadas do espaço construído, tratando-se dos resíduos do passado que podem ser evidenciados através da supressão, acumulação e superposição dos tempos, apresentando-se de forma isolada ou formando um conjunto arquitetônico. Essas formas pretéritas revelam-se no espaço através das paisagens.

Percebe-se ainda uma nova dimensão da racionalidade na organização sócio-espacial contemporânea revela seus valores e conteúdos através de fluxos, no que diz respeito à circulação, à informação e à comunicação, conectados aos fixos, termo referente aos objetos naturais e técnicos presentes nas formas da paisagem (SANTOS, 1988).

A valorização da área central de Florianópolis e a sua incorporação ao negócio do turismo não é um fato isolado. Este mesmo processo ocorreu na Rua das Flores em Curitiba, em São Luís do Maranhão, em Salvador, entre outras. Cada cidade encontra sua maneira de fazer sua revalorização da área central e incorporar a este, o contexto de preservação.

Já a expansão do turismo em Florianópolis, a qual se destaca por sua diversidade de paisagens (cultura, etnia, gastronomia, fauna, flora e de lugares exóticos, como belas praias), traz consigo a utilização das belezas naturais muitas vezes apenas aproveitadas em períodos sazonais, caracterizando, por conseguinte, um turismo tão-somente de sol \& mar. 
Desta maneira, constata-se como característica típica do turismo moderno, o fato de o homem causar modificações diversificadas para atender às suas necessidades e aos seus prazeres momentâneos, nem sempre - infelizmente - com preocupações de longo prazo. Para Xavier (2007) freqüentemente os lugares são vistos como simples referências espaciais ou como palcos para o desenvolvimento econômico, o que vem despertando preocupações em melhor conhecer a conduta das pessoas diante da expansão do turismo.

Os lugares vão sendo transformados, em locais turísticos, não apenas através de estratégias políticas e publicitárias ou pelo fato de que há sempre pessoas de passagem, mas porque esses movimentos de passagem trazem novos conteúdos e significados, por conseqüência, novas identidades (GUIMARÃES, 2006).

Assim, mostra-se que a prática do turismo constrói um espaço rico e complexo, ordenado com referência às intenções e experiências humanas, é nele onde nos prolongamos por meio de nossas ações e percepções buscando torná-lo um espaço social, integrado com múltiplas atividades comerciais, culturais e até mesmo geográficas.

Dessa maneira, este estudo busca uma interação com os fatores sociais e culturais, e articulados às dimensões econômicas, analisando a questão do turismo do ponto de vista mercadológico, como um objeto de diferentes consumos - produto da exploração capitalista.

É importante referenciar a abordagem perceptiva dos estudos do turismo, inserindo-o no cotidiano, no dia-a-dia da população, como uma atividade construtora e modificadora dos espaços, que busca produzir melhor qualidade de vida para as comunidades, alterando e criando novas territorialidades, já que o que, em tese, é bom para o turista, deve ser pensado, a priori, como benéfico, em seus mais diversos aspectos, para população local.

\section{Considerações finais}

Foi pensando neste sentido que se buscou abordar a atividade turística a partir do berço do surgimento da cidade, tendo em vista que o centro hoje está se dinamizando, tomando novas significações diferentes das originais. Incorporadas a este fenômeno, as ações de cunho turístico se tornam presentes buscando a inserção não só mais como um aspecto de resgate cultural, mas, sobretudo, por serem consideradas em seu papel enquanto meio transformador da paisagem e dos diversos objetos que compõem o seu entorno, sob amplos interesses sócio-econômicos. 
Sabe-se que a dinâmica urbana busca em sua essência qualificar as áreas centrais, principalmente históricas tornando-as referenciais e permitindo mantê-las vivas e integradas à cidade. Hoje a maioria das cidades possui uma dinâmica própria com atividades que desenvolvem em maior e menor escala uma relação social com o espaço urbano ocorrendo um processo contínuo de produção e transformação desta área: "Quando uma área passa por um processo de mudança, implica transformações nas relações sociais, econômicas e políticas, simultaneamente ocorrem mudanças em relação ao espaço que se transformará para adaptarse as novas exigências da sociedade" (FRESCA, 1990, p. 84).

Este processo de mudança contínua do espaço faz com que ocorra a dinâmica urbana, a qual possui uma relação com a dimensão temporal, já que resultam dos processos históricos, econômicos, políticos e sociais acontecidos na cidade.

A partir disso, torna-se relevante destacar que o Estado possui uma relação com o espaço no sentido que é um dos agentes da organização espacial das cidades. Com o intuito de valorizar novas áreas e buscar seu desenvolvimento, incentiva o deslocamento da população por meio de investimentos, expandindo a descentralização. Para isso, os órgãos públicos, estatais e os centros administrativos buscam nestes novos espaços "espacializarem”, visando criar novas centralidades vinculadas a estes os interesses do capital imobiliário.

Esta substituição das áreas centrais por outros bairros das cidades vem refletindo em muitas capitais brasileiras na falta de qualidade urbana dessas antigas áreas, através de problemas oriundos principalmente dos aspectos socioeconômicos, de transporte, de infraestrutura e de conservação das edificações (LOUREIRO, 2003).

O resultado desta descentralização traz como conseqüência para estas áreas centrais a perda da vitalidade e da dinâmica urbana. Tornando vários espaços subutilizados nos finais de semana e sendo somente aproveitados em horário comercial.

Como acrescenta Lacerda (1998), grande parte do estoque de área construída no centro histórico está desocupada ou subutilizada, pois as novas atividades não geram recursos suficientes para pagar os aluguéis e a manutenção que as edificações exigem para o seu funcionamento. Também não existe atividade econômica suficiente para ocupar o espaço vazio nas edificações verticais, o que acaba gerando uma ocupação clandestina danificando mais o imóvel.

Para buscar a reintegração destas áreas centrais tem-se como planos de ação apresentado por Del Rio (1996), a revitalização urbana que visa reidentificar o passado no 
presente, ressuscitando a tradição através da memória coletiva, mas sem inibir a modernidade. Isso mostra que é necessário este novo desenvolvimento respeitar e integrar-se às estruturas físicas e sociais já existentes. Além disso, para as áreas urbanas centrais que perderam sua vitalidade é possível resgatá-las através de um planejamento tornando estes espaços em turísticos:

[...] o planejamento de espaços turísticos, por meio de alocação de equipamentos diversos, garantirá uma permanência mais longa do visitante e uma maior satisfação em sua estada. É imprescindível, em um primeiro momento, disponibilizar uma infra-estrutura básica e buscar a conscientização da comunidade na qual se está inserindo. O planejamento de espaços urbanos permite uma melhor qualidade de vida para a população e certamente propicia uma imagem favorável ao turista, que, em geral, se desloca a fim de 'consumir' o turismo (DE ROSE, 2002, p. 41).

Assim, verifica-se que agregar a atividade turística como mais um serviço para a qualidade de vida da população é algo plausível de estudo, visto que a comunidade deve ser inserida como ator principal de uso desta infra-estrutura. Dessa forma, buscando o comprometimento e a colaboração de todos para a preservação e valorização destes espaços.

\section{REFERÊNCIAS BIBLIOGRÁFICAS}

BELTRÃO, L. M. V. A produção do espaço urbano em Florianópolis: a criação de aterros. Dissertação de Mestrado. Florianópolis, UFSC/CFH, 1989.

CARLOS, Ana Fani Alessandri. O lugar no/do mundo. São Paulo: Hucitec, 1996.

CRUZ. R. de C. A. da. Introdução à geografia do turismo. São Paulo, Roca, 2001.

CRUZ, Rita de Cássia A. da. Geografias do turismo de lugares a pseudo-lugares. São Paulo: Roca, 2007.

INTRATEXTOS, Rio de Janeiro. vol.2, nº 1, PP. 97 - 109, 2010. 
DEL RIO, V. Introdução ao desenho urbano no processo de planejamento. São Paulo, Pini, 1990.

DE ROSE, A. T. Turismo, Planejamento e Marketing. Barueri/SP, Manole, 2002.

FERNANDES, J. A. R. Cidade do Porto e área metropolitana do Porto: realidades e desafios. "História". III série, vol.1. FLUP, pp.127-143, 2000.

FRESCA, T. M. A dinâmica funcional da rede urbana do oeste paulista: estudos de casos - Osvaldo Cruz e Inubia Paulista. Dissertação de Mestrado. Florianópolis, UFSC/CFH, 1990.

GUIMARÃES, V. M. A modernidade e os encontros turísticos: turistas na barra da lagoa. Tese de Doutorado. Florianópolis, UFSC/CFH, 2006.

GUTIERREZ, R. Arquitetura latino-americana. Trad.: Isa Maria Lando. São Paulo, Nobel, 1989.

GUTIÉRREZ, R. O direito à memória: patrimônio histórico e cidadania. História, Memória e Comunidade: o direito ao patrimônio construído. São Paulo, pp. 121-127, 1992.

LACERDA, N. et al. Planejamento metropolitano no Brasil: uma proposta de conservação urbana e territorial. Disponível em: < http:// www.ceci-org.br>. Acesso em: 20 maio 2008.

LACAZE, J. P. La ville et l'urbanisme. Paris, Flammaron, 1995.

LOUREIRO, F. J. F. Dinamismo de áreas históricas centrais - Florianópolis e São Luís. Dissertação de Mestrado. Florianópolis, UFSC, 2003.

LUCHIARI, A.; MORATO, R. G.; KAWAKUBO, F. S. Mapeamento da qualidade de vida em áreas urbanas: conceitos e metodologias. Revista Terra Livre. São Paulo, v. 2, n. 21, pp. 241-248, 2003.

PARENAI, P. Análise urbana. Brasília, UNB, 2006. 
REIS FILHO, N. G. Espaço e Memória: conceitos e critérios de intervenção. O direito à memória: patrimônio histórico e cidadania. São Paulo, DPH, 1992.

SANTOS, M. Da sociedade à paisagem - O significado do espaço humano. Rio de LTC, 1978.

SANTOS, M. Metarmofose do espaço habitado: fundamentos teóricos e metodológicos da Geografia. São Paulo, Hucitec, 1988.

SANTOS, M. Espaço \& Método. São Paulo, Nobel, 1985.

SANTOS, M. Técnica, espaço, tempo - globalização e meio técnico-científico informacional. São Paulo, Hucitec, 1994.

SANTOS, M. A natureza do espaço. 3. ed. Edusp, São Paulo, 1999.

SEVERINO, A. J. Metodologia do trabalho científico. São Paulo, Cortez, 1996.

SILVA, J. B. et al. (org) Discutindo a cidade e o urbano. A cidade e o urbano. Fortaleza, EUFC, 1997.

SOUZA, Marcelo José Lopes de. Espaciologia: uma objeção (crítica aos prestigiamentos psedo-críticos do espaço social). Revista Terra Livre 5 - O espaço em questão, v. 5 (São Paulo: Marco Zero/AGB). Pp. 21-45, jul/dez. 1988.

VANCE, J. E. Focus on Downtown. In: Bourne, L. S. Internal streucture of the City Readings on space and environment. New York, Oxford University Press, 1971.

VAZ, N. P. O centro histórico de Florianópolis - espaço público do ritual. Florianópolis, UFSC, 1991.

XAVIER, H. A percepção geográfica do turismo. São Paulo, Aleph, 2007. 